\title{
Agôn
}

Revue des arts de la scène

Critiques | Saison 2010-2011

\section{Les visages de la monstruosité}

Obludarium, conception Matej et Petr Forman

\section{Caroline Châtelet}

\section{(2) OpenEdition \\ 1 Journals}

Édition électronique

URL : http://journals.openedition.org/agon/1693

DOI : 10.4000/agon.1693

ISSN : 1961-8581

Éditeur

Association Agôn

Référence électronique

Caroline Châtelet, «Les visages de la monstruosité », Agôn [En ligne], Critiques, mis en ligne le 05 juin 2011, consulté le 23 septembre 2020. URL : http://journals.openedition.org/agon/1693 ; DOI : https:// doi.org/10.4000/agon.1693

Ce document a été généré automatiquement le 23 septembre 2020

Association Agôn et les auteurs des articles 


\section{Les visages de la monstruosité}

Obludarium, conception Matej et Petr Forman

\section{Caroline Châtelet}

\section{RÉFÉRENCE}

Obludarium, conception Matej et Petr Forma. Spectacle en tournée du 24 mai au 2 juillet 2011 au Théâtre du Rond-Point

\section{NOTE DE L'ÉDITEUR}

Une première version de cet article est parue en février 2010 sur http://

www.ruedutheatre.eu

1 Défini comme un monde entre cirque, cabaret et cabinet des curiosités, Obludarium des Frères Forman ouvre les portes de sa baraque foraine. Un lieu étrange, où à l'architecture extérieure baroque répond une plongée dans un monde d'outredifformité conjuguant à loisir la monstruosité et la beauté. 


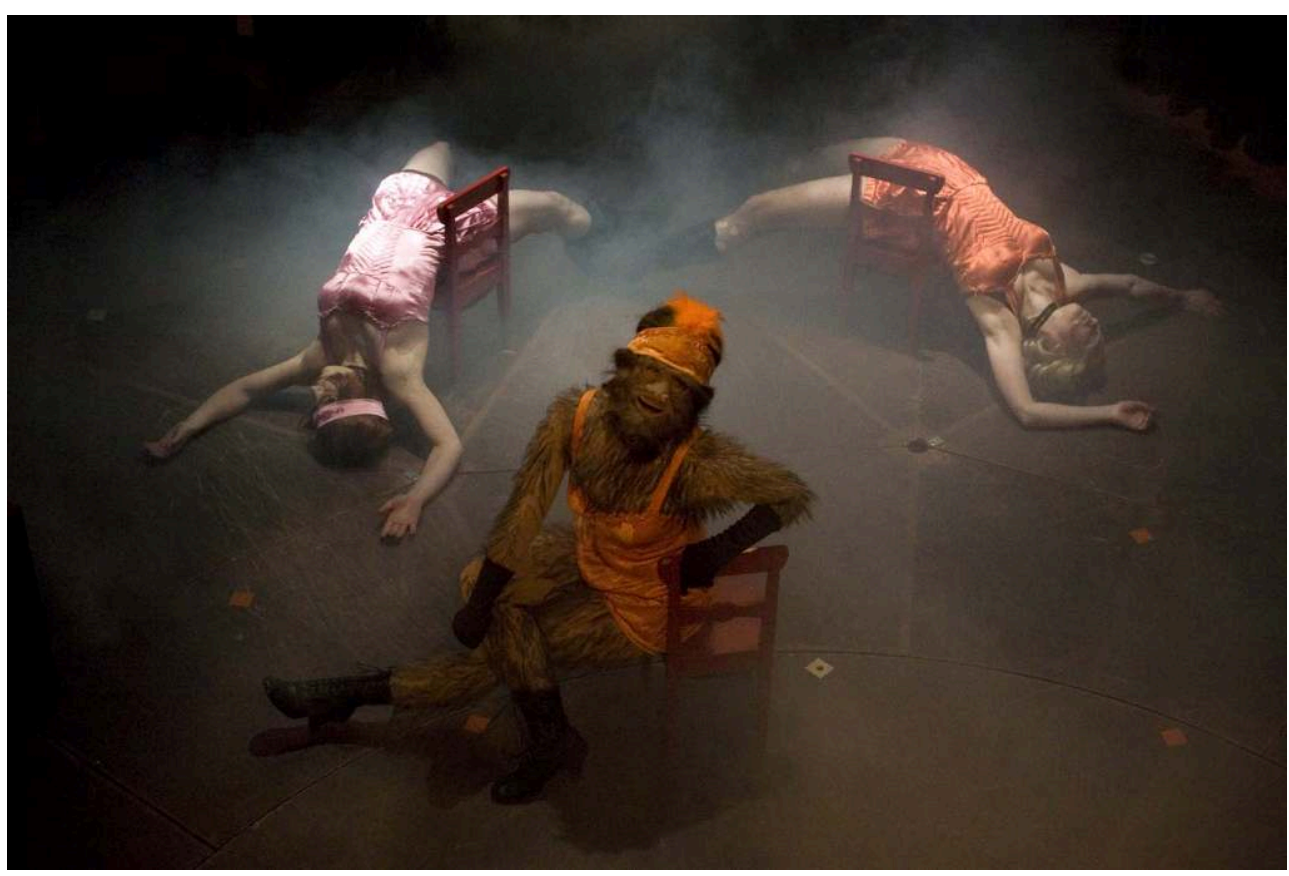

(C) Irena Vodakova

2 Avant d'évoquer ce spectacle, deux choses sur ses créateurs. Surnommés « les Frères Forman », les marionnettistes Matej et Petr se sont fait connaître en France lors de leur participation à la Volière du cirque Dromesko. Une aventure désormais mythique qui a, durant son existence, réuni de multiples circassiens sous une volière habitée par plusieurs centaines d'oiseaux. Mais Matej et Petr sont également les fils jumeaux du réalisateur Miloš Forman. Étrange coïncidence qui veut que ce soit d'artistes dont la gémellité exerce de tous temps un curieux pouvoir de fascination et d'attraction que naisse cette singulière parade. Comme si les Frères Forman partaient de la monstruosité originelle - non pas liée à une quelconque difformité mais attachée à une pure différence - pour construire leur monde bancal et troublant... Alors, ce monde, quel est-il ? Nommé Obludarium, il évoque par sa drôle de contraction entre le mot tchèque "obluda », " monstre ", et " planétarium » ou "aquarium » un lieu devant lequel on se plante afin d'observer des figures dont la différence - même minime - avec la normalité attire et dérange. Et avant même de pénétrer dans ce " chapiteau » inouï dont l'architecture, les couleurs bigarrées et les motifs aux effets d'optique uniques perturbent la perception, on comprend qu'on arrive aux portes d'un autre monde. En guise d'hôtesse, un forgeron massif et velu tout occupé à son ouvrage est installé à quelques mètres de l'entrée. Une façon de signaler que si le public se rend au spectacle, cet endroit est d'abord pour ses créateurs un lieu de travail.

Dans ce cabaret de bois où l'on se presse aux balustrades, l'étrange famille déploie, dans une succession de numéros, ses prouesses et ses difformités. Femme à barbe, forgeron chanteur lyrique, gymnaste au physique (presque) impeccable, "grosses têtes tchèques ", tous participent à cet univers baroque et fantastique. Nous sommes ici dans l'étrange, qui, par l'inquiétude qu'il provoque, peut basculer autant dans le merveilleux que dans l'horreur. Plongeant ses racines dans les versants forains du cirque traditionnel, Obludarium déploie la part de monstrueux propre au genre. Ainsi, dans chaque histoire - d'amour ou d'horreur, c'est selon -, le beau ne cesse de contaminer le 
hideux et la laideur la beauté dans une friction puissante. Rien n'est univoque, comme ce numéro onirique de danse de poissons qui vire à l'angoisse sourde par les lamentations stridentes d'une sirène. Ou cet affrontement entre le forgeron et une acrobate se muant en chants opératiques au lyrisme affirmé. Les rapports de force n'étant jamais définitifs, le public lui-même peut, à l'occasion, devenir le bouffon de la farce comme lors du jeu étourdissant et lancinant sur «Frère Jacques». En s'appropriant intégralement le genre et en jouant au passage sur l'exotisme et l'imaginaire liés à leurs contrées lointaines, les Frères Forman élaborent leur cirque. Un cirque total, un monde autonome qui, en se clôturant par l'ouverture du bar, rappelle que pour ces gens de foire l'art - et leur corps exhibé - est un moyen de subsistance... Et qu'à la sacralisation du spectacle, l'équipe préfère son association intime à la vie.

INDEX

Mots-clés : Obludarium, Forman (Matej), Forman (Petr), Théâtre du Rond-Point 